\title{
Turning Information Into Knowledge for Rangeland Management
}

\section{By Jason W. Karl}

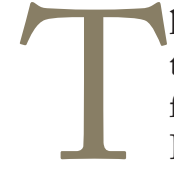

he time in which we live is often referred to as the "Information Age." We are surrounded by information, and sometimes are bombarded with it. But despite the incredible volume of available information, it never seems to be enough, or of the right type, or at the right time. Often, rangeland management decisions seem to be harder rather than easier to make. Compounding this problem is the ever-increasing variety and intensity of land uses and threats to rangeland systems such as fire or invasive species. This conundrum has highlighted the fact that information and knowledge are two very different things; although in some cases we might be drowning in the former, the latter is in short supply.

The knowledge that supports natural resource management traditionally has resided with the decision-maker, and has been passed down through formal education as well as on-the-job (or perhaps more appropriately "on-the-land") training. Much of it also has been generated by these same individuals, through observations of how the land responds to different types of management through decades of drought recovery. However, we are seeing high turnover in rangeland management staff, coupled with an unprecedented rate of new and competing uses and threats to rangeland resources. Among private rangeland owners, lands that historically were handed down through the family are being sold more frequently to third parties, ${ }^{1}$ and the land knowledge that was accumulated over generations is at risk of being lost. An alternative system for storing and sharing knowledge urgently is needed. In addition to focusing on capturing the collective knowledge of land managers, which is at great risk of being lost, this system also must integrate existing scientific knowledge with new knowledge that constantly is being generated. Some of the tools generating much of this new knowledge are described in this special issue of Rangelands, guest edited by myself and Jeffrey E. Herrick, Research Soil Scientist, in association with the staff and facilities of the USDA Agricultural Research Service's Jornada Experimental Range.
An appreciation of how we derive information and knowledge to make land management decisions could help in creating systems to improve the decision-making process. A common representation of how we take individual observations and create knowledge is the "Data-InformationKnowledge Hierarchy” (Fig. 1). Originally described by H. Cleveland in $1982,{ }^{2}$ this theory has continued to evolve. ${ }^{3,4} \mathrm{It}$ posits that the accumulation and synthesis of data (facts, experiences, and empirical observations) form the basis of information. The accumulation and interpretation of information, in turn, creates knowledge. In the hierarchy, data have value when they are combined for a purpose, and this process creates information. Knowledge is interpreted information that can be applied to new situations. Although the emphasis in the last 30 years on development of information systems (e.g., geographic information system [GIS]) and decision-support tools has been invaluable to resource management, significant gaps still exist in the basic knowledge of ecosystem processes that are the foundation for being able to understand and apply available information. Additionally, because much of rangeland management knowledge resides with individual managers or land owners, it is not widely accessible and is in danger of being lost unless new approaches to cataloging and sharing knowledge are developed.

These new approaches must focus on making information more widely available and exploiting emerging information and networking technologies. However, in some cases, data simply aren't available to answer a particular question, but in many other cases, valuable information is available but is not accessible..$^{5}$ Of the information that is accessible, only a portion of it is actionable (relevant and of sufficient quality to be useful for a management need). Given recent strides in information technologies, including databases, searching, and online data services, it now is possible to start assembling new knowledge systems about rangelands. A knowledge system must be able to integrate 


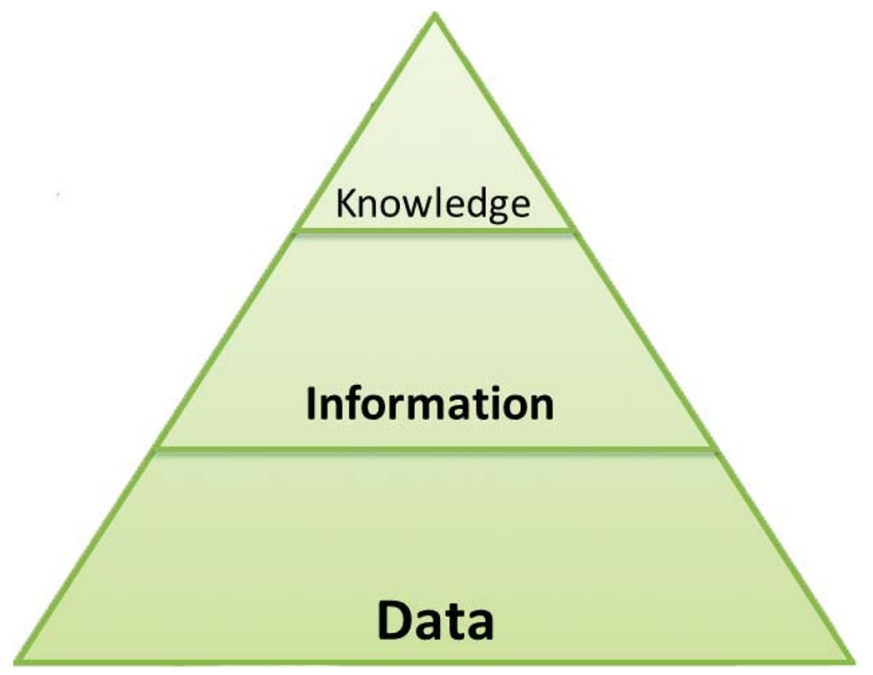

Figure 1. The "Data-Information-Knowledge Hierarchy" is a common way of representing how knowledge is created. In this model, data represent facts known, observations made, or measurements taken. Information is data that are integrated with existing information for a particular purpose. Knowledge is the application of information to make a decision or achieve a specific goal. Modified from Rowley (2006). ${ }^{3}$ Reprinted with permission.

information for various objectives and catalog existing knowledge (such as that which resides with managers and owners and is currently at risk of being lost). It also must be able to capture the evolution (and in some cases revolution) in knowledge as new information is gathered and old information is reevaluated.

The kind of knowledge system that will be capable of meeting the needs of resource managers is not a database application that will reside on some server, and it will not come about quickly or as the result of a single group of individuals. It will evolve as scientists, technology specialists, managers, and biologists find ways to integrate the everexpanding array of information systems and tools to meet their needs. The papers in this special issue describe tools and techniques that could play a role in creating knowledge from information about rangelands. The tools and techniques highlighted in this issue of Rangelands were selected because they have immediate application, and illustrate the various types of tools necessary to support management decision-making.

Data form the backbone of information and knowledge, and managing the diversity of rangeland uses requires highquality data upon which the status and trend of resources can be determined. Consistency in how rangeland ecosystems are monitored not only will help improve the quality of data collected but also the ability of expensive data to be used to answer multiple monitoring objectives. Riginos et al. introduce a new and easy-to-implement approach to collecting and monitoring data that can be used in rangelands across the globe by people with little education or training. Toevs et al. discuss a comprehensive approach to monitoring and assessment being adopted by the Bureau of Land Management that also is consistent with other monitoring programs implemented across the United States on private lands (including the National Resources Inventory). This system integrates consistent field-measured indicators, methods, and sample design with remote-sensing techniques.

Useful information can only be created from data if those data are collected, stored, and analyzed in an efficient and error-free way. Much monitoring data that has been collected over the years never has been used, in part, because the data still reside on paper field forms or in one-off databases. New mobile technologies have dramatically improved the potential for collecting data electronically in the field, eliminating the potential for transcription errors. Furthermore, the use of a consistent data standard improves the likelihood that data can be reused to help address other objectives. Courtright describes a sophisticated database for collecting data in the field using tablet computers, organizing it in the office, and creating reports or supporting statistical analyses.

With the scale and variety of rangeland uses and threats continuing to increase, much effort is being invested in developing new techniques to get quantitative information to monitor large landscapes. Although landscape-wide remote sensing techniques (e.g., image classification) have shown promise for informing those in rangeland management, many of these approaches either remain beyond the capabilities of agency personnel or private landowners to implement or lack the specificity needed for local-level management. An alternative that has emerged is interpretation of very-high-resolution (VHR) aerial images to directly estimate rangeland attributes similar to how they would be measured in the field. Booth and Cox discuss tools for analyzing aerial photographs, for cover, composition, or density using point-based and line- or area-based techniques. Schrader and Duniway also detail a point-based tool for making cover estimates from VHR images, but with a focus on training and calibrating personnel interpreting the aerial images.

An integral part of a knowledge system is being able to apply current understanding of how systems work to evaluate the impact and magnitude of processes such as erosion, and predict the possible outcome of potential management actions. Traditionally, this type of knowledge has resided with people who had years of experience in specific rangeland systems. Increasingly, however, this knowledge has been harvested and combined with research studies to create robust models that illustrate our current understanding of how rangeland ecosystems work. These can be conceptual models such as the state-and-transition models found in ecological site descriptions (see the December 2010 issue of Rangelands), or mathematical and statistical models of ecosystem processes. For the latter, scientists have recognized the need to make these models available to managers and ranchers in straight-forward, simple-to-understand 
formats so they can be used in decision-making. Goodrich et al. outline a suite of water erosion models for rangelands that were built into accessible web and GIS interfaces.

The papers mentioned above focus on the collection and organization of information that can be synthesized into knowledge, but by themselves are not sufficient to form a knowledge system. A knowledge system must capture the interpretations of information for different uses. The same technologies that we now use to keep in touch with our friends and families, to learn new things, and understand current events, can form the basis for a rangeland knowledge system. Two papers detail several projects that make use of wikis, content management systems, and interactive web tools to begin this process. These projects go beyond the simple literature or internet searches that are widely used, because they provide interpreted summaries and syntheses of pertinent sources related to specific topics. Karl et al. detail a tool for helping rangeland professionals figure out which monitoring or assessment techniques could be appropriate for informing a particular management question. They also highlight an extensive wiki (a website that can be edited by a community of people) that describes the advantages, limitations, and rangeland applications of each of the more than 100 included techniques. Hutchinson et al. review three related websites that catalog and summarize knowledge related to management and monitoring of rangelands manifest in sources such as scientific literature, extension publications, and management summaries. What makes these sites unique is the use of new, more targeted search techniques, interpretive summaries, and the ability for users to contribute their own knowledge.

These papers represent only a small portion of the many new tools and techniques that are now available for creating actionable information for rangeland management. The challenge now is to start integrating these technologies into knowledge systems. The good news is that the explosion of new, socially-interactive technologies such as wikis, crowdsourcing, news and blog feeds, and internet-connected mobile devices have broadened the realm of possibilities for assembling a knowledge system. For example, many resource managers are already using the iPhone and Android application "SoilWeb" to rapidly identify the suite of soils mapped at a specific location in the United States using the phones' built-in global positioning system (GPS). 6 The challenge will be to figure out how to combine scientific and traditional knowledge sources in a way that increases understanding of rangeland systems and promotes good decision-making.
In their book Wikinomics: How Mass Collaboration Changes Everything, ${ }^{7}$ D. Tapscott and A. D. Williams quote the CEO of Proctor and Gamble, A. G. Lafley, as saying, "Someone outside your organization today knows how to answer your specific question, solve your specific problem, or take advantage of your current opportunity better than you do. You need to find them, and find a way to work collaboratively and productively with them." If, as a body of rangeland professionals, we are to make effective management decisions and respond to existing and emerging threats, this cooperative spirit must pervade the field. Given resource constraints and the sheer number of management and monitoring needs, it is no longer reasonable to expect that the knowledge and experience that reside with one or a handful of individuals (no matter how smart they are) will be sufficient. Deriving the knowledge that is necessary to influence and justify management or policy action across a range of scales requires a collaborative effort to share information, knowledge, and experience to respond to local and global needs. The techniques and technologies described in this issue of Rangelands can help form the foundation for the land management knowledge system of the future.

\section{References}

1. Gosnell, H., J. H. Haggerty, and W. R. Travis. 2006. Ranchland ownership change in the Greater Yellowstone Ecosystem, 1990-2001: implications for conservation. Society and Natural Resources 19:743-758.

2. Cleveland, H. 1982. Information as a resource. The Futurist December:34-39.

3. Rowley, J. 2006. The wisdom hierarchy: representations of the DIKW hierarchy. Journal of Information Science 33:163-180.

4. Stenmark, D. 2001. The relationship between information and knowledge. In: Proceedings of IRIS 24; 11-14 August 2001; Ulvik, Norway. Goteborg, Sweden: Information Systems Research in Scandinavia (IRIS) Association. Available at: http://citeseerx.ist.psu.edu/viewdoc/download?doi=10.1.1.21. 965\&rep=rep1\&type=pdf. Accessed 14 July 2011.

5. Peters, D. P. C. 2010. Accessible ecology: synthesis of the long, deep, and broad. Trends in Ecology and Evolution 25:592-601.

6. Beaudette, D. 2011. SoilWeb for the iPhone. Available at: http://casoilresource.lawr.ucdavis.edu/drupal/node/886. Accessed 18 May 2011.

7. Tapscott, D., and A. D. Williams. 2006. Wikinomics: how mass collaboration changes everything. New York, NY, USA: Penguin Group. 351 p.

Author is Research Ecologist, USDA-ARS Jornada Experimental Range, Las Cruces, NM 88003, USA, jkarl@nmsu.edu. 